\title{
Hardness, Microstructure and Strain Distributions in Commercial Purity Aluminum Processed by Multi Directional Forging (MDF)
}

\author{
Natanael Geraldo Silva Almeida ${ }^{a}$, Pedro Malaquias Araújo Stemler ${ }^{a}$, Cleber Granato de Faria ${ }^{a, b}$, \\ Pedro Henrique Rodrigues Pereira', Maria Teresa Paulino Aguilar', Paulo Roberto Cetlin ${ }^{e *}$ (1) \\ ${ }^{a}$ Universidade Federal de Minas Gerais (UFMG), Programa de Pós-Graduação em Engenharia \\ Metalúrgica, Materiais e de Minas, Pampulha, MG, Brasil \\ ${ }^{b}$ Centro Universitário Newton Paiva, CEP 30494-230, Belo Horizonte, MG, Brasil \\ 'Universidade Federal de Minas Gerais (UFMG), Departamento de Engenharia de Metalúrgica e de \\ Materiais, Pampulha, MG, Brasil \\ ${ }^{d}$ Universidade Federal de Minas Gerais (UFMG). Departamento de Engenharia de Materiais e \\ Construção, Pampulha, MG, Brasil \\ eUniversidade Federal de Minas Gerais (UFMG). Departamento de Engenharia Mecânica, \\ Pampulha, MG, Brasil
}

Received: June 18, 2020; Revised: August 1, 2020; Accepted: August 4, 2020

\begin{abstract}
Severe plastic deformation (SPD) of metals leads to their strengthening and grain refinement, but to low uniform elongations. Low Strain Amplitude Multi Directional Forging (LSA-MDF) is an important method for increasing this low uniform elongation. The application of workpieces of SPD-processed materials requires that their distributions of mechanical properties, microstructures and deformation be as homogeneous as possible. Analyses of these distributions after LSA-MDF have not been found in the literature, and are presented in the current investigation utilizing microhardness measurements, optical and electronic microscopy and finite element simulations. LSA-MDF causes higher strains, mcrohardeness and structural distortions in the central regions of the specimens than at their edges and corners. In addition, LSA-MDF utilizing confined compressions seems to be the preferred processing route, due to its ease and to the more homogeneous microhardness, microstructure and strain distributions in relation to other experimental procedures.
\end{abstract}

Keywords: Aluminum, Severe Plastic Deformation, Multi Directional Forging, Microstructures, Distribution of strain and microhardness.

\section{Introduction}

Severe Plastic Deformation (SPD) greatly refines grains of metals ${ }^{1}$, leading to a remarkable strengthening and to the possibility of achieving high strain rate superplasticity ${ }^{2}$. Grain refinement is also important in the die filling and surface characteristics of micro-formed parts ${ }^{3}$, which have been gaining importance due to the growing needs for miniaturization of components ${ }^{4}$. The most utilized SPD processing techniques are Equal-Channel Angular Pressing (ECAP) ${ }^{5}$, High-Pressure Torsion (HPT) ${ }^{6}$ and Multi Directional Forging (MDF) ${ }^{7}$, also known as Multi Axial Compression ${ }^{8}$ or Multi Axial Forging9. HPT produces small, thin discs; ECAP can supply bulk specimens, but involves high friction between the material and the dies and problems such as plastic instabilities, cracks and specimen segmentation in the processing of difficult-to-work materials ${ }^{2}$. According to Sakai et al..$^{10}$, MDF has the following advantages over other SPD processing techniques: i) possible application to large (industrial) workpieces ii) allows the evaluation of the in-situ stress-strain characteristics of the material during processing iii) its application is simple since any testing machine or industrial press can be utilized, at

*e-mail: pcetlin@demec.ufmg.br various temperatures and strain rates and iv) the frequent changes in straining direction propitiates the formation of equiaxed structures. MDF is also an adequate processing route for difficult to work materials ${ }^{11-13}$.

SPD processes have been covered in many studies in the literature and frequently focus on the evolution of the material microstructures and mechanical behavior ${ }^{2,11,14}$. Experimental problems in MDF derive from the specimen distortions caused by the free sequential compressions ${ }^{15}$. As a consequence, the measured $i n$-situ stress-strain curves display inadequate results ${ }^{16,17}$, demanding the re-machining of the specimens after each compression ${ }^{18}$ or after a few compression steps ${ }^{19}$; such re-machining is time consuming, complex and costly ${ }^{20}$. One additional problem caused by distorted specimen faces is the measurement of the imposed strain, since the specimen displays a varying height ${ }^{21}$. It has also been reported that the distorted shape and surfaces of MDF specimens are a problem in ultrasonic measurements in the material ${ }^{22}$. MDF with confined compressions has been used in order to solve these problems ${ }^{23,24}$, and three such approaches are found in the literature: (i) confined channel die pressing, where the material is processed under 
plane strain and flow confinement occurs along one of the directions orthogonal to the compression direction during all the compression, but only at the end of the compression for the other orthogonal directions ${ }^{21,25-27}$, (ii) processing under conditions very similar to those under CCDP, but with confinement only along one of the directions orthogonal to the compression one that establishes the plane strain (hereafter denominated "open plane strain") ${ }^{8}$. The lack of confinement in the other direction orthogonal to the compression direction causes distortions in the unconfined face of the workpiece ${ }^{28}$, eventually leading to the need of its flattening through machining ${ }^{23}$, (iii) Multi-Directional Confined Forging (MDCF), where the lateral expansion of the material caused by the compression occurs initially in a way similar to the free compression, and then is equally confined in both directions orthogonal to the compression direction $^{20}$, leading to flat lateral faces of the specimen after each compression step. In addition, it should also be remembered that the strain path under plane strain confined processing is not the same of that in free MDF or MDCF, thus leading to differences in the microstructural and mechanical properties evolution of the material ${ }^{29}$.

The understanding of the relationship between the microstructures and properties of materials and of the strain distribution in specimens processed through SPD has progressed appreciably in the last decade $\mathrm{e}^{30,31}$. Heterogeneous strain distributions cause non-uniform microstructures and mechanical properties at different regions of the processed material $^{28}$, which is undesirable in the production of material to be used in any given application. The available studies on strain distributions often utilize two techniques: microhardness measurements and finite element simulations. The former has been used for the various SPD processes and their variables; an example (among many others) is the analysis of ECAP for various materials, such as pure Aluminum, 6061 Aluminum alloy and $\mathrm{Cu}-\mathrm{Zr}$ alloy ${ }^{32-34}$, covering the influence of the external die angle ${ }^{35,36}$ and the annealing of the material after 1 ECAP pass ${ }^{37}$. Microhardness measurements, for example, has been used for HPT, covering studies along the disc diameters of pure Aluminum and Aluminum alloys ${ }^{38,39}$, $\mathrm{Zn}-22 \% \mathrm{Al}$ alloys ${ }^{40,41}$, Mg alloys AZ31 and AZ91 ${ }^{31,42}$, and along the thickness of disks of pure Aluminum ${ }^{37,43-45}$. Microhardness distribution analyses in MDF utilizing microhardness measurements have been less frequent than for ECAP and HPT, and have been performed along a line in the workpiece for open plane strain $\mathrm{MDF}^{8}, \mathrm{CCDP}^{24}$, free compressions $^{46}$ or over the full specimen cross-section in open plane strain ${ }^{28}$, and CCDP ${ }^{47,48}$. The results report a higher hardness in the central regions of the workpieces than in the regions close to their borders, and that hardness in both regions tend to saturate as high levels of strain are reached. Investigations involving finite element simulations are not as common as those performed through microhardness measurements. Hao Huang and Jing Zhang ${ }^{49}$ report, for MDF of Mg alloy AZ31 at $\sim 300^{\circ} \mathrm{C}, \sim 350^{\circ} \mathrm{C} \mathrm{e} \sim 400^{\circ} \mathrm{C}$, that strain homogeneity decreases as the total imposed strain rises. Guo et al. ${ }^{12}$ report an opposite result for the same material, similarly to the report for CCDP by Magalhães et al. ${ }^{48}$ for Copper, where the strain homogeneity increases as the accumulated strain rises.
SPD remarkably strengthens materials and refines their grains, but there is a drastic decrease in the uniform elongation of the material, caused by its low work hardening capacity under further deformation ${ }^{30}$. As a consequence, these materials do not perform well under processing where tensile deformations predominate. Recent studies covering techniques for increasing the work hardening capacity of materials previously deformed by SPD have emphasized the application of a few cycles of LSA-MDF ${ }^{16}$ in commercial purity Aluminum. LSA-MDF has received very limited attention in the literature ${ }^{13}$ and, as far as the authors are aware of, no results have been presented for the distribution of hardness, microstructures and strain in the processed specimens. It should be remarked that, due to the low strain amplitude in LSA-MDF, its use in order to reach the high strains typical of SPD processes would involve a very high number of compressions and thus a low productivity. The objective of the present study is the evaluation of the distributions of hardness, microstructures and strain in the LSA-MDF of commercial purity Aluminum processed under three conditions: free compressions, free compressions with specimen re-machining after each compression, and MDCF. Analyses were performed through microhardness measurements, finite element simulations and microstructural analyses employing Optical Microscopy (OM) and Electron Back Scattered Diffraction (EBSD).

\section{Experimental Procedure}

The material was a commercially pure Aluminum (99.77wt \% Al, 0.146wt \% Fe, $0.060 \mathrm{wt} \% \mathrm{Si}$ ), received in the as-cast condition; the billet had a diameter of $\approx 150 \mathrm{~mm}$ and was $\approx 1,500 \mathrm{~mm}$ long. The material underwent an initial ECAP pass followed by annealing at $673 \mathrm{~K}$ for $1 \mathrm{~h}^{17,20}$.

Three types of MDF processing were utilized in the present research, in order to compare the influence of the processing on the results: (i) free compression of the specimens, without any lateral confinement of the material flow, (ii) free compression of re-machined specimens after each compression step, in order to obtain flat surfaces to contact the compression platens in the following compression, according to a procedure already utilized previously ${ }^{17}$ and (iii) compression with confined dies (Multi-Directional Confined Forging, MDCF), as described elsewhere ${ }^{20}$. Specimens were machined out of the annealed material as cuboids with dimensions $13.00 \times 12.52 \times 12.06 \mathrm{~mm}$ along directions $\mathrm{X}, \mathrm{Z}$ and $\mathrm{Y}$ of the specimen respectively, for both free and MDCF, and with dimensions $15.58 \times 15.00 \times 14.45 \mathrm{~mm}$ for processing with re-machining of the specimens after each compression step ${ }^{17}$. These larger initial dimensions were adopted in order to have specimens with approximately the same dimensions, after the complete processing of the specimens and along the three adopted MDF routes. For the case of the re-machined specimens, the successive machining of the specimen faces decreases the specimen dimensions. For the free compressions and MDCF, compressions start along the specimen axis displaying the longest edge length (X axis, measuring $13.00 \mathrm{~mm}$ ) down to $12.06 \mathrm{~mm}$, imposing a strain of $\Delta \varepsilon=0.075$. After this first compression, the edge along the $Z$ direction of the specimen will be $13.00 \mathrm{~mm}$ long, and along the $\mathrm{Y}$ direction $12.52 \mathrm{~mm}$ long. The new 
longest dimension, along the specimen $\mathrm{Z}$ axis, will then be compressed to $12.06 \mathrm{~mm}$; finally, the edge along the $\mathrm{Y}$ axis will also be compressed from $13.00 \mathrm{~mm}$ to $12.06 \mathrm{~mm}$. After this last compression, the specimen will have been subjected to a total strain $\varepsilon=3 \times 0.075=0.225$ and will have returned to its initial dimensions along the original $\mathrm{X}, \mathrm{Z}$ and $\mathrm{Y}$ axes, corresponding to a so-called MDF "cycle". For the case of re-machined specimens, compressions also started along the longest compression and imposed a strain $\varepsilon=0.075$; the second compression was preceded by the machining of the face to be compressed and the measurement of the initial height of the specimen along the normal to this plane, followed by a compression with $\varepsilon=0.075$ and so on. One and four such cycles were employed leading to a total accumulated strain $\varepsilon=0.225$ and 0.9 , respectively ${ }^{16,20}$.

Microhardness measurements and microstructural characterizations were performed on a specimen mid-plane normal to the $\mathrm{X}$ direction and after 1 and 4 MDF cycles, as illustrated in Figure 1. The sectioned specimens were mechanically ground down to a grit paper with 400 grains $/ \mathrm{cm}^{2}$ and then electrolytically polished at $\approx 35 \mathrm{~V}$ for $\approx 45 \mathrm{~s}$ with a solution of $700 \mathrm{ml}$ ethylic alcohol, $120 \mathrm{ml}$ of distilled water, $100 \mathrm{ml}$ butyl glycol and $68 \mathrm{ml}$ perchloric acid, with a stainless steel cathode. Vickers microhardness measurements were performed with a Mitutoyo model MVK-H1 tester, with a load of $2.943 \mathrm{~N}$ applied for $15 \mathrm{~s}$. Microhardness mapping involved measurements distributed on the specimen section, with a distance of $0.5 \mathrm{~mm}$ between the indentations both along directions $\mathrm{Y}$ and $Z$. In the case of MDCF specimens, where the specimen cuboid shape is maintained throughout the processing, the measurements reached a distance of $0.5 \mathrm{~mm}$ from the specimen edge, as described in Figure 1. Free MDF involves lateral expansion of the specimens and concave specimen surfaces, and re-machined specimens employ initially larger specimens than for free MDF and MDCF; for these cases, microhardness measurements started at

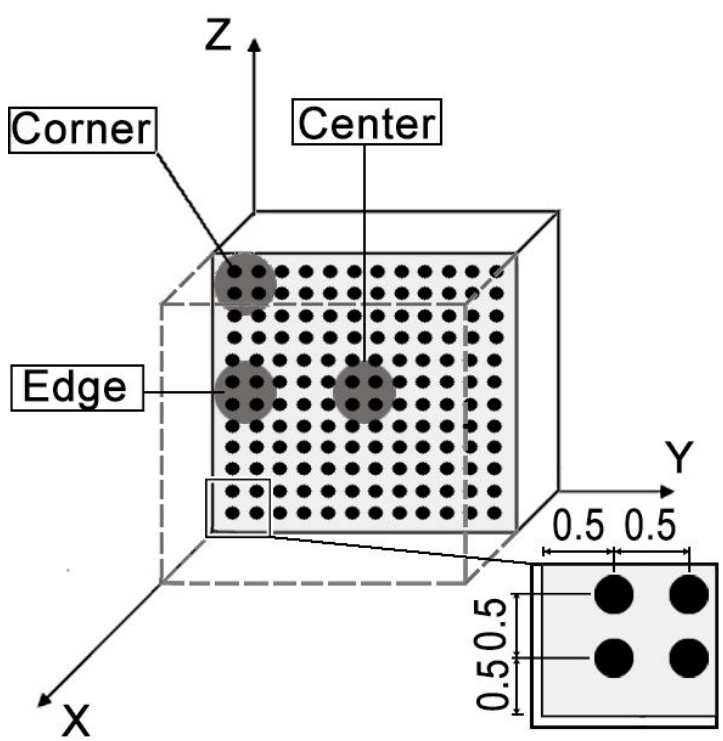

Figure 1. Specimen section and locations where microhardness measurements were taken and regions (center, edge and corner) where microstructural evaluations were performed. the center of the specimens and the same mesh points as in MDCF. As a result, the distance of the outermost measurements from the specimen borders were larger than $0.5 \mathrm{~mm}$. The results reported in the present report cover only the area of the mesh displayed in Figure 1.

Microstructural analyses were performed in the specimen centers, edges and corners, as indicated in Figure 1, for all processing conditions. Optical Microscopy (OM) utilized a Leica DM4500 P LED microscope. Electron Back Scattered Diffraction (EBSD) employed a FEI Scanning Electron Microscope (SEM) model Quanta FEG 3D and the ATEX software for the EBSD data analysis. A step size of $810 \mathrm{~nm}$ was used; it was verified that no relevant differences were detected in the EBSD results when lower step sizes were employed, for the present objectives. Specimen surface preparation was the same as that for microhardness measurements, but OM included an anodizing process after the mechanical and chemical polishing, using $20 \mathrm{~V}$ for $360 \mathrm{~s}$ and a solution of $4.5 \mathrm{ml}$ fluoroboric acid in $200 \mathrm{ml}$ distilled water and a stainless steel cathode. Images were collected using polarized light.

Computational finite element simulations of the processing were completed for the three adopted processing routes, using the commercial DEFORM 3D V11.1 software. Free compressions without re-machining of the specimen allowed the gravitational positioning of the specimens caused by the bulged lateral surfaces to be compressed, caused by the previous compression. The re-machining of the specimen was performed numerically through the minimal elimination of the bulged volume in the face to be compressed, till a flat face was obtained, normal to the respective cuboid axis. MDCF and free compression simulations involved rigid dies. The constitutive behavior of the material was taken as the envelope of the individual stress-strain curves for every compression step with confining dies, already reported by the present authors ${ }^{20}$. The material was considered as isotropic and insensitive to strain rate variations. The coefficient of friction between the material and the compression dies was taken as 0.4 , which led to a very similar external shapes of the specimens in the simulation and in the experiments with specimen re-machining. The element density was 10.11 elements/ $\mathrm{mm}^{3}$, the punch speed was $0.05 \mathrm{~mm} / \mathrm{s}$ and the punch displacement per step was $0.047 \mathrm{~mm} / \mathrm{step}$.

It is recognized that the simulation results for the specimen shape, strain and stress distributions are approximate due to the following points: the constitutive behavior is described by a monotonically increasing flow stress corresponding to the envelope of the individual stress stress-strain curves for each MDCF compression. These display decreased yield strengths in relation to the corresponding flow stress in the envelope curve, as well as initial mild stress peaks ${ }^{20,50}$, associated with the strain path changes as the specimen is rotated. These phenomena cannot be accounted for in the current state of finite element simulations. In addition, material anisotropy is always present due to its crystallographic texture and was not considered in the simulations. As a consequence, the distortions in the specimens can be underestimated and thus their influence on the obtained strain distributions can be below the experimental ones. 


\section{Results}

\subsection{Specimen shape and microhardness distributions}

Figure 2 exhibits the shapes of the mid-section of the processed specimens (see Figure 1), as well as the microhardness distributions on these sections, for the three MDF techniques in the present investigation and for 1 and $4 \mathrm{MDF}$ cycles. Free
MDF without specimen re-machining leads to increasingly rhomboidal specimens, starting from the $1^{\text {st }}$ MDF cycle (Figure 2a) and more distorted by the successive MDF cycles, as evidenced in Figure $2 b$ (after the $4^{\text {th }}$ MDF cycle). MDF with free compressions also led to higher hardness values along the smaller rhomboid diagonal, again starting from the $1^{\text {st }}$ MDF cycle (Figure 2a) and enhanced after the $4^{\text {th }}$ MDF cycle (Figure $2 b$ ).

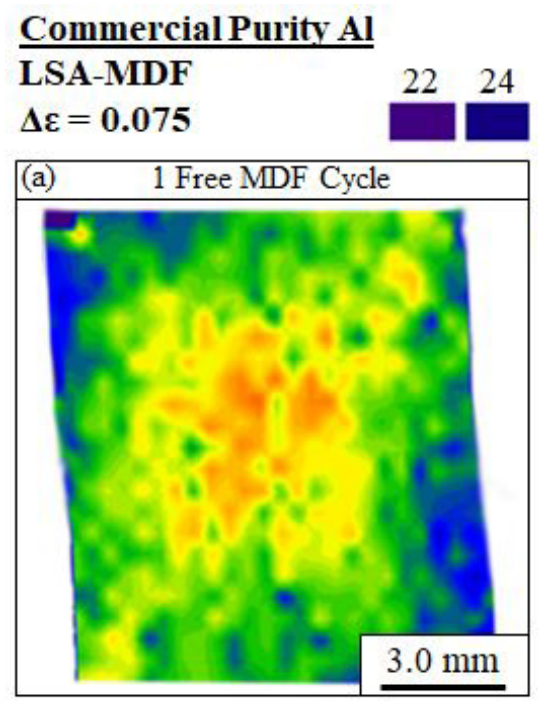

Hardness (HV)
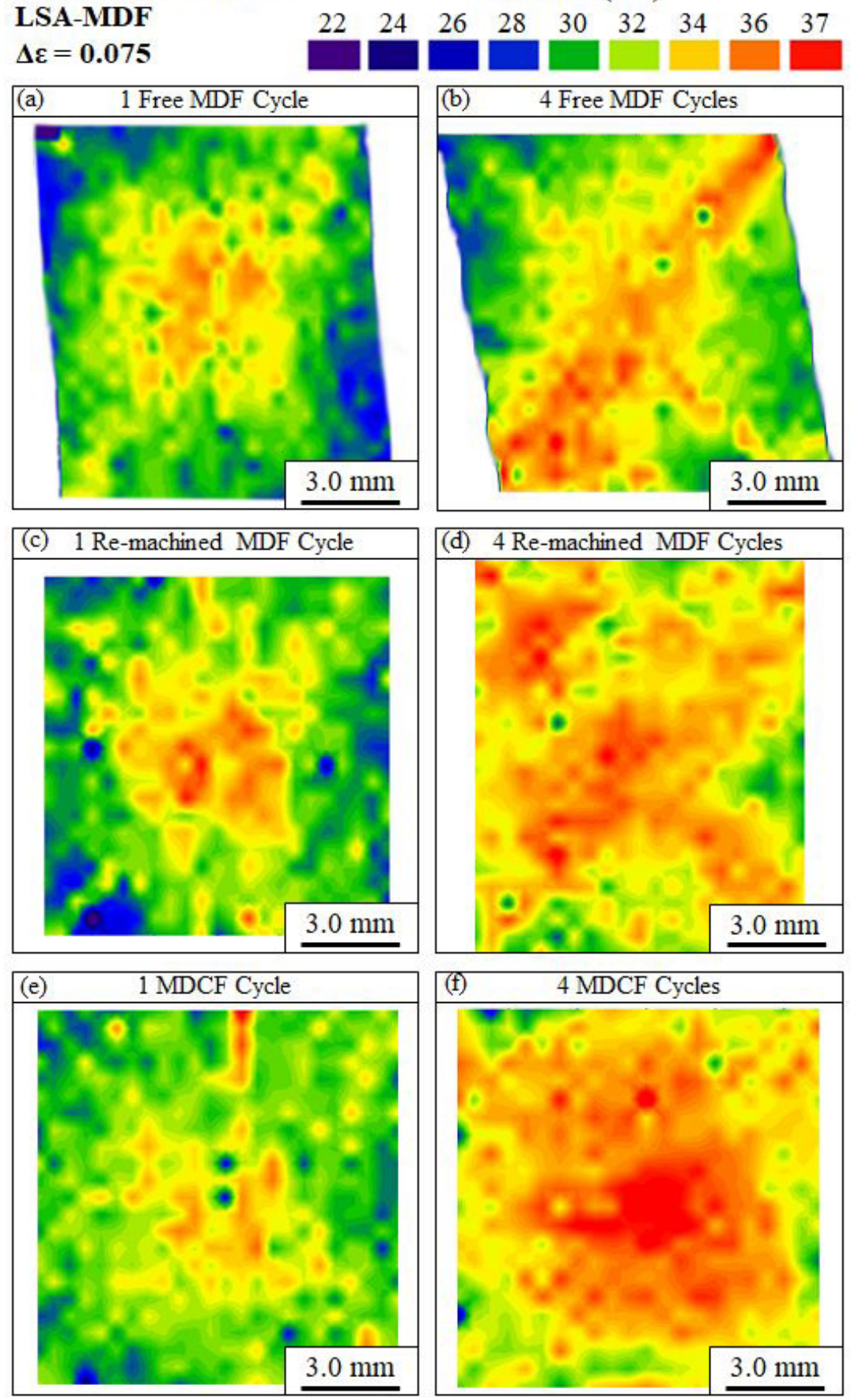

Figure 2. HV microhardness distributions for specimens processed for 1 and 4 MDF cycles respectively for (a, b) free MDF, (c, d) free MDF and re-machined specimens, and (e, f) MDCF. 
The results for processing with re-machined specimens and with confined compressions (Figure $2 \mathrm{c}-2 \mathrm{f}$ ) consistently reveal that the problems reported above for free compressions were eliminated. The dimensions of specimens re-machined after each compression are somewhat different from those for free compressions and for MDCF, since machining obviously changes the specimen dimensions. In the present experiments, the anisotropic lateral expansion of the specimens caused more material removal by machining normal to the $\mathrm{Y}$ direction than normal to the $\mathrm{X}$ and $\mathrm{Z}$ directions, in order to flatten the specimen face to be compressed and thus to a narrower specimen along the Y direction. This is connected to the crystallographic textures developed by the initial ECAP + annealing treatment and by the successive MDF compressions. For $1 \mathrm{MDF}$ cycle (Figures $2 \mathrm{c}$ and $2 \mathrm{e}$ ) the central regions of the specimens are harder than those closer to the specimen edges, as already indicated in the literature ${ }^{28}$. The MDCF specimen has a lower hardness in the central region than the re-machined specimens, but a more uniform microhardness distribution. This tendency is eliminated after the $4^{\text {th }}$ MDF cycle, but processing with re-machined specimens leads to a microhardness distribution where the specimen diagonals display higher hardness than the rest of the specimen, and an " $\mathrm{X}$ " shaped high hardness region can be observed. This situation was not detected for MDCF processing (Figure 2e and 2f); in addition, $4 \mathrm{MDCF}$ cycles lead to a larger harder central region than the other two procedures.

\subsection{Microstrutures}

\subsubsection{Optical microscopy (OM)}

Figure 3 displays the OM (Optical Microscopy) images of the central regions of the specimens (see Figure 1) processed for 1 and 4 cycles of free MDF, free MDF with re-machined specimens and MDCF.
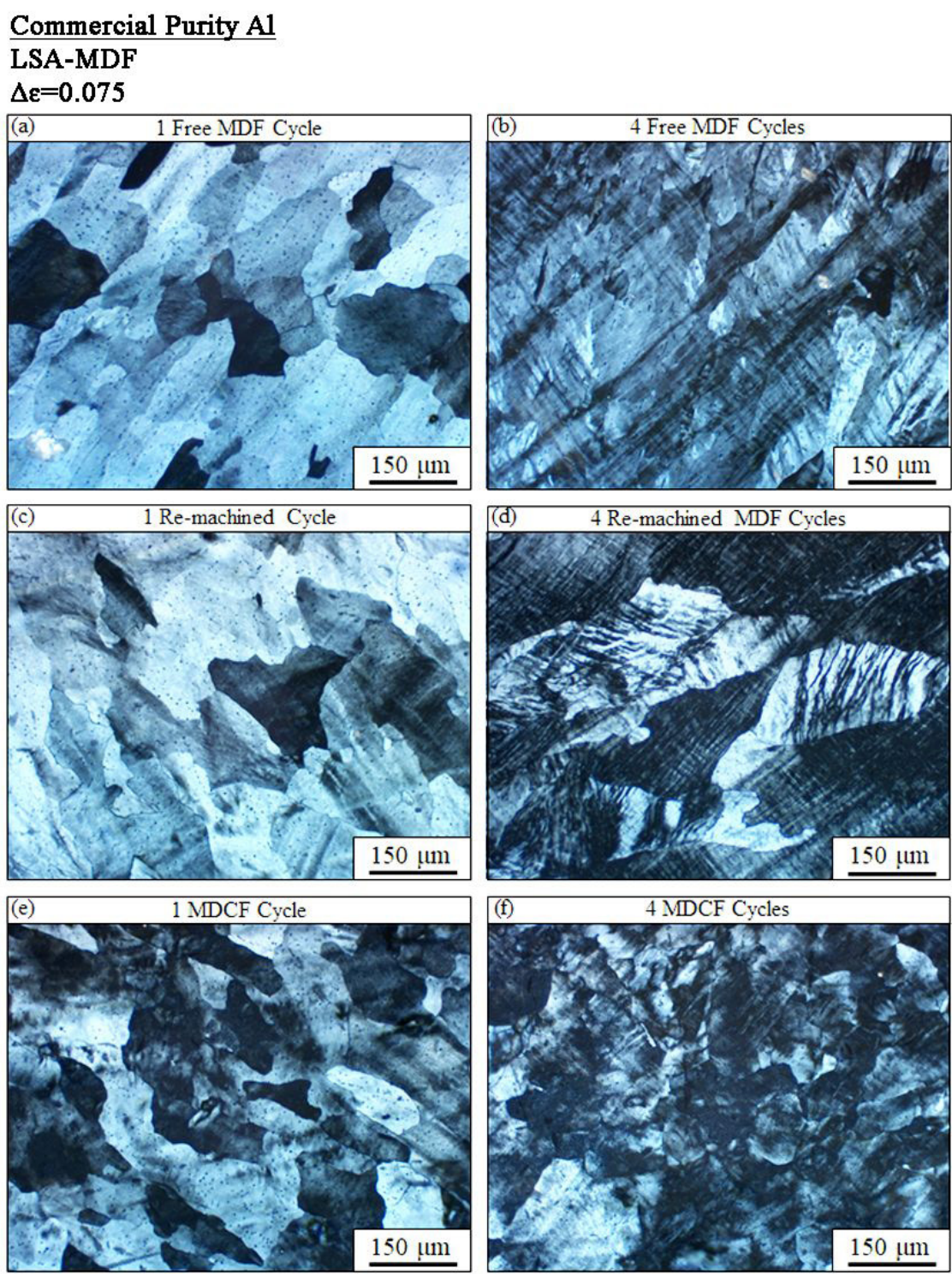

Figure 3. OM images of the specimen microstructures at the central regions after 1 and 4 MDF cycles respectively for (a, b) free MDF, $(c, d)$ free MDF and re-machined specimens, and (e, f) MDCF. 
For the central region and $1 \mathrm{MDF}$ cycle Figure 3a indicates that little deformation seems to have occurred for free MDF, since the grains are basically undistorted and exhibit practically no deformation bands. Re-machined specimens (Figure 3c) show some distortions of the grains and deformation bands, that would be caused by a higher deformation than in free MDF (Figure 3a). MDCF (Figure 3e) led to grains with somewhat more distortions and deformation bands than in the re-machined specimens. The images for the central region and $4 \mathrm{MDF}$ cycles (Figures 3b, 3d and 3f) also suggest a similar increase in the deformation as the different processing routes are adopted, involving more grain distortions and deformation bands.

The above results for the central region of the specimens are similar to those observed in the specimen edges and corners (see Figure 1) especially after $1 \mathrm{MDF}$ cycle. The qualitative situation after $4 \mathrm{MDCF}$ cycles is also similar to that in Figure 3, but the level of grain distortions and intensity of shear banding in the edge and corner regions is lower than in the central region. These differences, however, are not very appreciable.
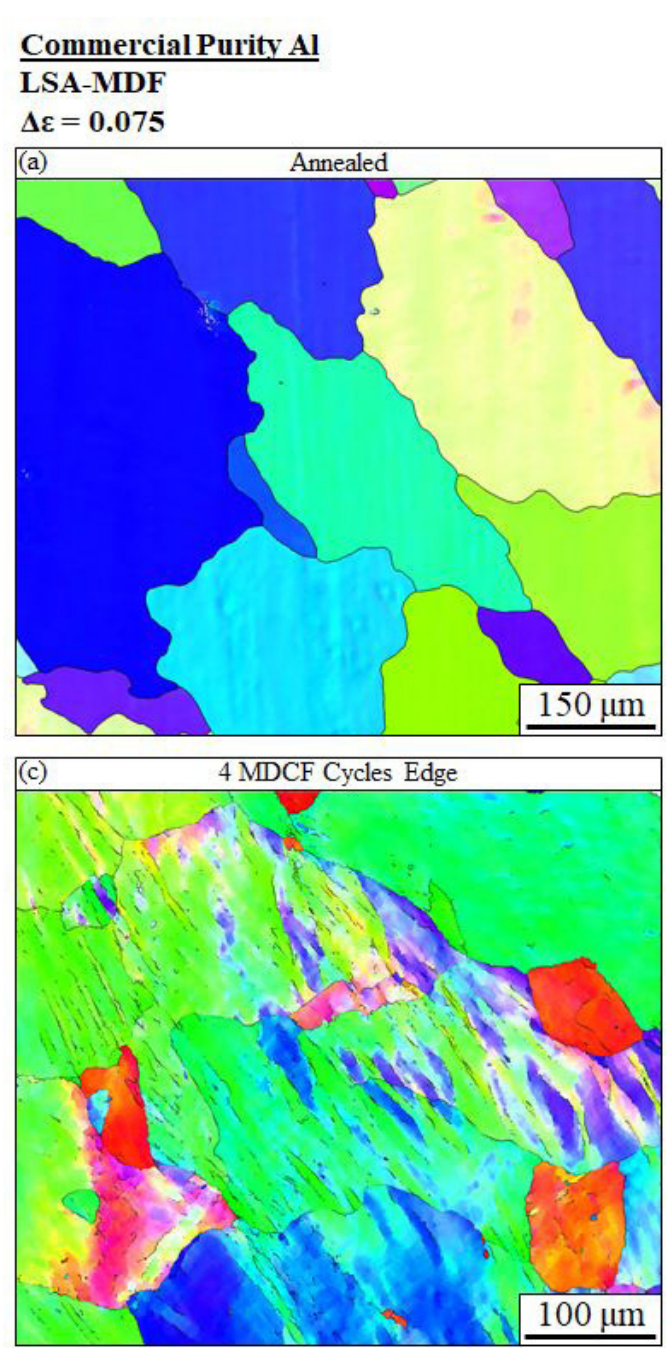

\subsubsection{Electron Microscopy}

An electron microscopy analysis was performed in the annealed material and at the central, edge and corner regions of a specimen processed after 4 MDCF cycles; these results can be extended to the other two processing routes, as indicated by the microhardness and OM studies. Figure 4a corresponds to the annealed material, Figure $4 \mathrm{~b}$ to the central specimen region, Figure $4 \mathrm{c}$ to the edge region and Figure $4 \mathrm{~d}$ to the corner region. The black lines in the OIM maps correspond to grain boundaries with misorientation angles above $5^{\circ}$ and allow their easier visualization. The color hues observed in the deformed materials (Figures $4 b, 4 c, 4 d$ ), correspond to small differences in the spatial orientation of the various regions, associated with the formation of substructures in the material inside the original grains, which are more equiaxed in the central region (Figure $4 \mathrm{~b}$ ) and more elongated in the edge and corner areas (Figures $4 \mathrm{c}$ and $4 \mathrm{~d}$ ). Some of these regions with color hues are surrounded by black lines, indicating a disorientation above $5^{\circ}$; in addition, some grains without internal color hues are also surrounded by black lines, suggesting the presence of a single grain orientation.
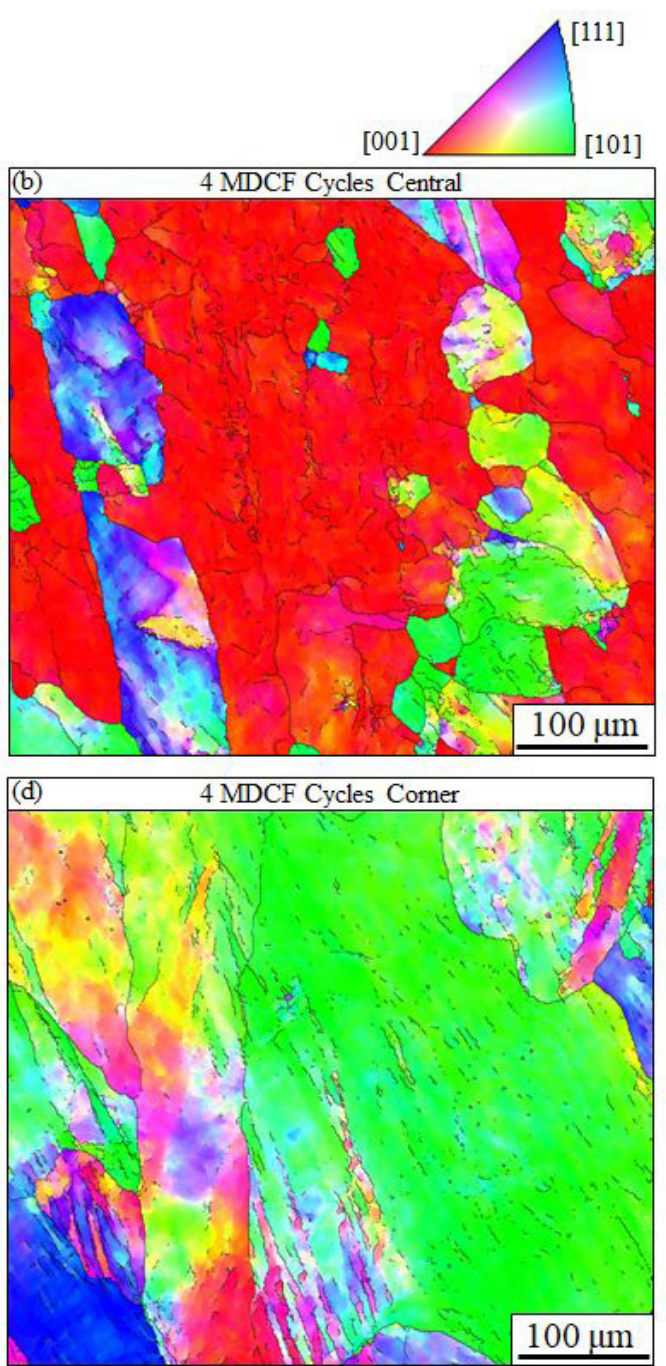

Figure 4. Orientation Image Mapping (OIM) of the (a) annealed material and after 4 MDCF cycles at the, (b) central, (c) edge and, and (d) corner specimen regions. 


\subsubsection{Numerical simulations}

Figure 5 shows the results of the numerical simulations predictions for the distribution of strain and shape in the specimen mid-planes for 1 and 4 MDF cycles and for free MDF, free MDF with re-machined specimens and MDCF. The dimensions of the re-machined specimen after $1 \mathrm{MDF}$ cycle are obviously higher than of the other specimens, since it will be successively machined till reaching approximately the same dimensions of the other specimens after 4 MDF cycles.

For the case of free compressions, the experimental distortions in the shape of the specimens displayed in Figures $2 \mathrm{a}$ and $2 \mathrm{~b}$ were not replicated in the simulation results, probably as consequence of the lack of crystallographic texture effects in the simulations. In addition, no " $X$ " shaped deformation pattern (see Figure 2d) was exhibited in any simulation. A higher strain was observed in the central regions of all specimens, in accordance with the previous findings based on microhardness measurements and microstructural analyses. The simulations also indicate that the central, more deformed region of the specimens is somewhat larger for the re-machined specimens than for the free compressions and MDCF; this is a consequence of the elimination of the outermost, less deformed regions of the specimens, due to their machining. The maximum strain in the central region of the specimens after $4 \mathrm{MDF}$ cycle is about 1.4, higher than the applied external strain (0.9) and after 1 MDF cycles is about 0.26 , again higher than the external strain $(0.225)$.

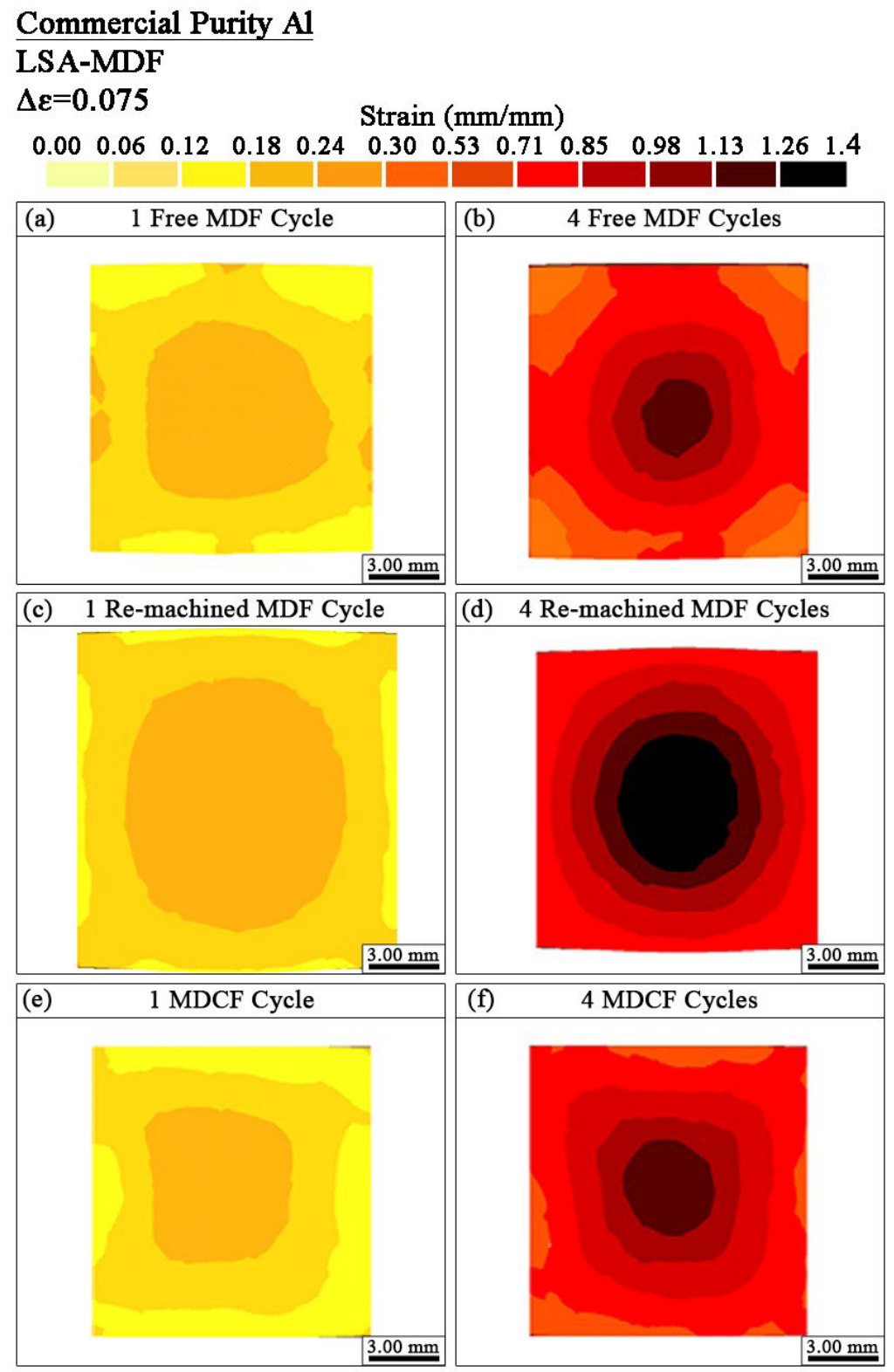

Figure 5. Numerical simulations prediction for the distribution of strain in the specimen mid-planes for 1 and 4 MDF cycles respectively for $(a, b)$ free MDF, (c, d) free MDF and re-machined specimens, and (e, f) MDCF. 


\section{Discussion}

\subsection{Specimen shape and microhardness distributions}

The results displayed in Figures $2 \mathrm{a}$ and $\mathrm{b}$ indicate that free MDF leads to specimen distortions and to a heterogeneous strain distribution with higher hardness along the smaller diagonal of the distorted rhomboid. The literature also reports that free MDF is conducive to specimen distortions; Zhu et al. ${ }^{15}$ show a specimen cross-section exhibiting even a concave lateral shape. Armstrong et al. ${ }^{19}$ state that re-machining of specimens was necessary after a few MDF cycles in order to eliminate the specimen distortions, but does not show any example of the distortions. Free MDF of Aluminum seems thus inconvenient as a SPD processing technique, from the point of view of specimen distortions and microhardness heterogeneities.

The average hardness values for the situations described in Figure 2 are 30.7, 31.1 and 31.2 HV after $1 \mathrm{MDF}$ cycle and 32.2, 33.5 and 33.7 $\mathrm{HV}$ after $4 \mathrm{MDF}$ cycles for free MDF, free MDF with re-machined specimens and MDCF, respectively. The hardness of Aluminum 1070 after rotary swaging up to a deformation of 1 , which is above the present strain of 0.9 for $4 \mathrm{MDF}$ cycles, has been reported as $35.5 \mathrm{HV}$; in addition, the initial hardness of this material is practically identical to that in the present study ${ }^{51}$. These results are consistent with the present ones.

The results displayed in Figure $2 \mathrm{c}$ - $\mathrm{f}$ show that MDF with re-machined specimens and MDCF lead to higher hardness in the central regions of the specimens than at their borders. In addition, 4 cycles of MDF with re-machined specimens led to higher hardness along the two specimen diagonals displaying a " $\mathrm{X}$ " shaped harder region; similar results have already been reported in the literature for the free MDF of Aluminum ${ }^{15}$ and for the MDF of Titanium processed in a channel die under open plane strain ${ }^{28}$.

Microhardness profiles along the $\mathrm{Y}$ direction of the specimens at their $\mathrm{Z}$ direction mid-height were extracted from the microhardness maps data for 1 or 4 MDF cycles and the three processing routes. For a given distance from the center of the specimen, the 4 vertical microhardness measurements vertically around the centerline, spaced by $0.5 \mathrm{~mm}$ (see Figure 1), were considered for their averages and dispersion bars, similarly to the procedure adopted in the literature ${ }^{33}$. The results are displayed in Figures $6 \mathrm{a}, 6 \mathrm{~b}$ and $6 \mathrm{c}$, for free MDF, MDF with re-machined specimens and for MDCF, respectively. The horizontal line in these figures corresponds to the average hardness in the annealed specimen. The results in Figure 6 confirm that the central part of the specimens is harder than the regions closer to their borders. No results were found in the literature for the LSA-MAC of Aluminum up to the total deformations reported in the present investigations. On the other hand, the average hardness in the central and border regions for the $\mathrm{Al}-4 \% \mathrm{Cu}$ alloy, after open plane strain MDF with a strain amplitude of 0.47 and after 15 compressions (total average deformation 7.05) also show that the hardness in the central region was also higher than in the border of the specimen ${ }^{8}$.

The measurement dispersions, represented in Figure 6 by the error bars, are often substantially higher for processing with $1 \mathrm{MDF}$ cycle than for 4 cycles. This is associated with the shape of the stress-strain curve of the material, which is typical for FCC metals with high stacking fault energy, where lower strains are linked to higher work hardening rates than higher strains. The theoretical average strain in the specimens after $1 \mathrm{MDF}$ cycle is 0.225 and after $4 \mathrm{MDF}$ cycles 0.9 . Hardness is directly linked to the material flow stress $^{26}$; as a consequence, at lower average strains, any local strain heterogeneities will lead to larger hardness variations than for higher average strains, as often indicated in the dispersion bars in Figure 6. A similar situation is reported in the literature, for microhardness measurements in A1 99.99\% processed by 1 and 4 ECAP passes ${ }^{33}$.

\section{Commercial Purity Al LSA-MDF $\Delta \varepsilon=0.075$}
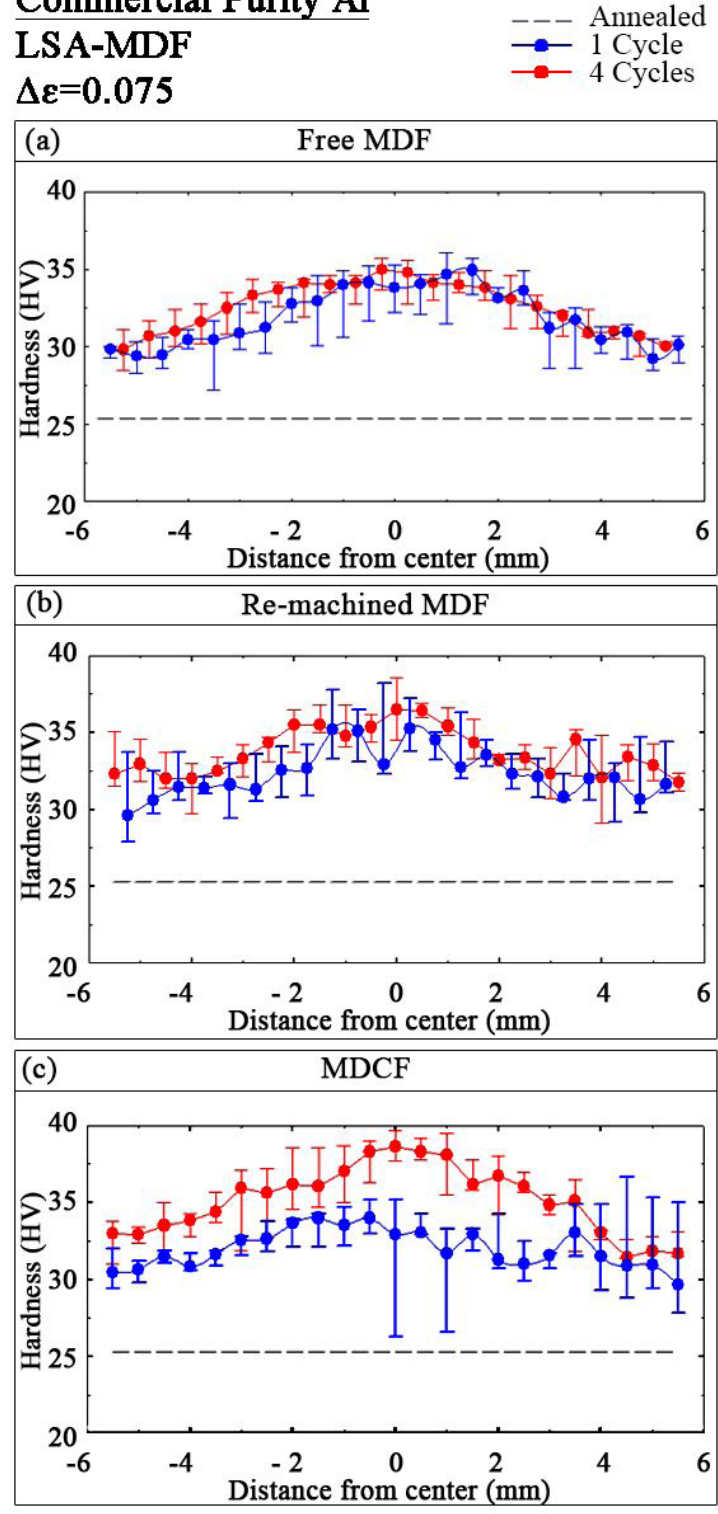

Figure 6. Microhardness measurements along the width of the mid-section of the processed specimens and at its mid-height, for 1 or $4 \mathrm{MDF}$ cycles with (a) free MDF, (b) free MDF with re-machined specimens, and (c) MDCF (Multi Directional Confined Forging). 
The comparison of Figures $6 \mathrm{a}$ and $6 \mathrm{~b}$ indicates that free MDF with re-machined specimens (Figure 6b) led to somewhat higher hardness at the specimen borders than without such re-machining (Figure 6a). Re-machining eliminates the specimen lateral bulges caused by their compression, which are regions less deformed than the central specimen regions ${ }^{15}$. The specimens where no re-machining was performed thus contain lateral regions less deformed and thus softer than those in the re-machined specimens.

MDCF does not lead to lateral bulges in the specimen, due to the confinement with the die walls; in contrast to free MDF and to MDF with re-machined specimen, some additional straining and work hardening should thus occur in the lateral faces of the specimens. When the specimens are rotated, these harder regions cause more deformation in the central specimen regions than in the other two processing routes and, as a consequence, to a greater difference in the hardness curves for 1 and $4 \mathrm{MDF}$ cycles, as shown in Figure 6c, in comparison with similar curves in Figures $6 \mathrm{a}$ and $6 \mathrm{~b}$, where the difference in strains caused by 1 or 4 MDF cycle seems to have not caused any appreciable hardening. Such lack of hardening is similar to that for 1 and 4 ECAP passes (involving a much higher applied strains) in high purity Aluminum ${ }^{33}$. These authors also report that, after 1 ECAP pass (average deformation of $\approx 1$ ) the hardness in the specimen varies from 30 to $45 \mathrm{HV}$, which is a higher range of values than that observed in the present results (from about 26 to $34 \mathrm{HV}$, for free compressions). For the average strain levels in the present investigations, HPT leads to much higher microhardness heterogeneities than any of the present MDF procedures ${ }^{39}$.

From the points of view of specimen distortions, microhardness distributions and ease of processing, MDCF seems to be the preferable route for LSA-MDF processing.

\subsection{Microstructures}

The optical and electron microscopy results displayed in Figures 3 and, 4, respectively, where microstructural features in the center of the specimens are more refined than at their edges and corners, are in accordance with reports in the literature, such as those of Zhu et al. ${ }^{15}$ for the free MDF of high purity Aluminum. In addition, these microstructural features are in agreement with the results based on the hardness distributions (Figure 2) and profiles (Figure 6), where hardness is higher in the central parts of the specimens than in their borders.

The OIM results (Figure 6), indicate a relatively strong preferential orientation of the grains around the $<110>$ and $<100>$ directions and is typical of FCC materials subjected to compression ${ }^{52,53}$.

Figure 7 displays the grain boundary characteristics at the central, edge and corner regions of a specimen processed after 4 MDCF cycles. Figures $7 \mathrm{a}$ and $7 \mathrm{~b}$ refer to the central specimen region, Figures $7 \mathrm{c}$ and $7 \mathrm{~d}$ to the edge and Figures $7 \mathrm{e}$ and $7 \mathrm{f}$ to the corner regions. The color lines in Figures $7 \mathrm{a}, 7 \mathrm{c}$ and $7 \mathrm{e}$ correspond to ranges of grain disorientations; red lines represent grain boundaries misorientation angles in the range of $2^{\circ}$ to $5^{\circ}$, the green lines to the range $5^{\circ}$ to $15^{\circ}$ and the dark blue lines to angles above $15^{\circ}$. The first two groups are usually called Low-Angle Grain Boundaries (LAGBs) and the third group High-Angle Grain Boundaries (HAGBs). Figures 7a, 7c and 7e indicate the presence of dislocation cells/subgrains in the material in all three examined specimen regions, confirming the formation of substructures suggested by the color hues in the OIM images in Figure 6. These substructures are basically equiaxed in the central region (Figure $7 \mathrm{a}$ ) and elongated in the edge and corner regions (Figures $7 \mathrm{~d}$ and $7 \mathrm{f}$ ). It is generally recognized that dislocation substructures in FCC metals with a high stacking fault energy (SFE) initially form in an elongated/lamellar aspect, and then, as strain is raised, become equiaxed ${ }^{54}$. This is in agreement with previous microhardness and OM results, which indicate the occurrence of higher deformations in the central region of the specimen than at its edges and corners. Figures $7 \mathrm{~b}, 7 \mathrm{~d}$ and $7 \mathrm{f}$ display the grain disorientation histograms for the three regions of the specimen. These distributions are similar and involve a low fraction of HAGBs; there is a small tendency for a higher fraction of HAGBs in the central region (0.038), in comparison with the corner $(0.031)$ and edge $(0.022)$ regions. This is probably connected to the increasing strain as one considers the edge, corner and central regions of the specimen, causing an increasing refinement of the structure. On the other hand, the situation should be viewed cautiously, since the differences in the measured values of HAGB fractions are low.

There was a pronounced grain refinement after the $4 \mathrm{MDF}$ cycles for all processing conditions. The initial grain size of the annealed material was $\sim 170 \mu \mathrm{m}$ and the final grain size, considering only HAGBs (High Angle Grain Boundaries, with disorientation angles $\theta>15^{\circ}$ ) in the central region of the specimens was $30 \mu \mathrm{m}$ as measured through the OIM images.

\subsection{Simulations}

The simulation results displayed in Figure 5 are in accordance with previous indications for the observed strain distribution, based on microhardness measurements and microstructural analyses. A higher strain is indicated for the central region of the specimen than at its edges and corners For free compressions, however, the simulations did not predict specimen distortions similar to those experimentally found, for the reasons already discussed.

The most homogeneous deformation distributions after 4 MDF cycles was obtained with specimens re-machined after each compression step. This is a consequence of the repeated removal of the outermost, less deformed regions of the specimen by machining. As already discussed, this procedure is time consuming, expensive and complex. A comparison of the strain distribution after $4 \mathrm{MDF}$ cycles under free compression (Figure 5b) and with MDCF (Figure 5f), where specimen distortions were neglected for the free compression, indicates that MDCF leads to a somewhat higher uniformity of strain distribution than free compressions. 

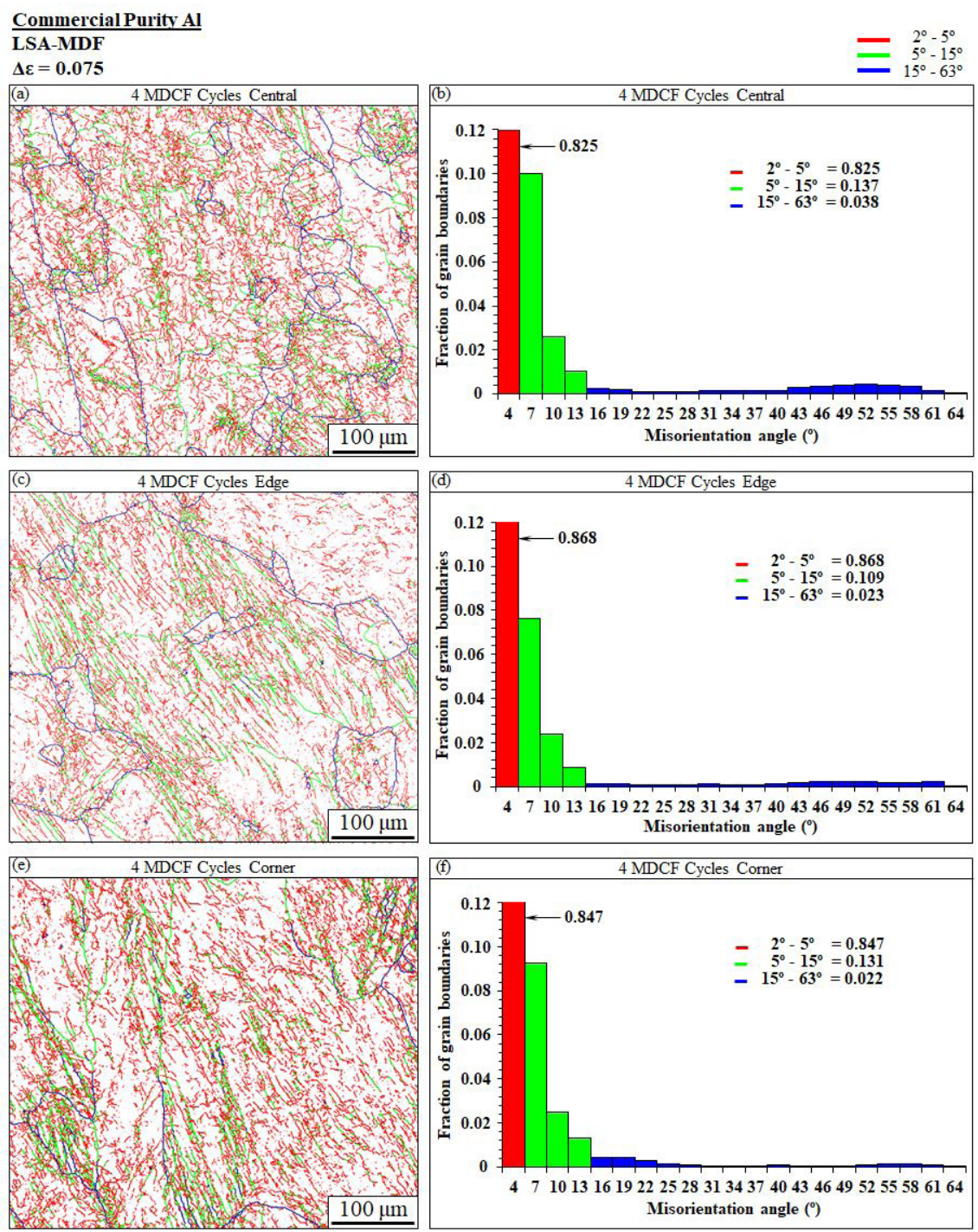

Figure 7. Grain boundary characteristics and distribution of grain disorientations of the material after 4 MDCF cycles, respectively $(\mathrm{a}, \mathrm{b})$ central specimen region, $(\mathrm{c}, \mathrm{d})$ edge specimen region, and $(\mathrm{e}, \mathrm{f})$ corner specimen region.

\section{Conclusions}

The present paper focuses on the analysis of the distributions of microhardness, microstructures and effective strain associated with Low Strain Amplitude MDF (LSA-MDF), after 1 and 4 LSA-MDF cycles. The results indicate that:

1. MDF under free compressions led to specimen distortions and to heterogeneous microhardness distributions. The specimens developed rhomboid sections and microhardness was higher along the shorter rhomboid diagonal than along the longer one. MDF with remachined specimens and MDCF (Multi directional Confined Compressions) eliminated these problems;

2. Microhardness measurements, microstructure analysis and numerical simulations of specimens after LSA-MDF with re-machined specimens and with MDCF indicate that these processing techniques lead to a higher strain in the central region of the specimens than in the regions closer to the specimen faces;

3. When re-machined specimens are utilized, the outermost regions of the specimen, which display lower deformations than the central regions, are successively removed by machining; as a consequence, the microhardness and strain distributions in remachined specimens is somewhat more homogeneous than under MDCF. Specimen re-machining is complex, time-consuming and costly;

4. The distribution of microstructures for all the LSA-MDF processing routes was similar; the central area of MDCF specimens displayed more equiaxed and refined grain structures than the corner and edge regions;

5. From the point of view of deformation through LSAMDF, MDCF seems to be the preferred route, due to 
its simplicity, low cost ease and its microhardness, microstructure and strain distributions, in relation to the other procedures (free compressions and compressions with re-machined specimens).

\section{Acknowledgements}

Material was supplied by Novelis do Brasil. Coordenação de Aperfeiçoamento de Pessoal de Nível Superior - Brasil (CAPES) - Finance Code 001 and CNPq (National Council for Research and Technological Development) Grant 301034/2013-3 financed this research.

\section{References}

1. Langdon TG. The principles of grain refinement in equal-channel angular pressing. Mater Sci Eng A. 2007;462:3-11.

2. Langdon TG. Twenty-five years of ultrafine-grained materials: achieving exceptional properties through grain refinement. Acta Mater. 2013;61:7035-59.

3. Xu J, Shi L, Wang C, Shan D, Guo B. Micro hot embossing of micro-array channels in ultrafine-grained pure aluminum using a silicon die. J Mater Process Technol. 2015;225:375-84.

4. Fu MW, Chan WL. A review on the state-of-the-art microforming technologies. Int J Adv Manuf Technol. 2013;67:2411-37.

5. Valiev RZ, Langdon TG. Principles of equal-channel angular pressing as a processing tool for grain refinement. Prog Mater Sci. 2006;51:881-981.

6. Zhilyaev AP, Langdon TG. Using high-pressure torsion for metal processing: fundamentals and applications. Prog Mater Sci. 2008;53:893-979.

7. Sakai T, Belyakov A, Kaibyshev R, Miura H, Jonas JJ. Dynamic and post-dynamic recrystallization under hot, cold and severe plastic deformation conditions. Prog Mater Sci. 2014;60:130207.

8. Xu X, Zhang Q, Hu N, Huang Y, Langdon TG. Using an Al-Cu binary alloy to compare processing by multi-axial compression and high-pressure torsion. Mater Sci Eng A. 2013;588:280-7.

9. Estrin Y, Vinogradov A. Extreme grain refinement by severe plastic deformation: A wealth of challenging science. Acta Mater. 2013;61:782-817.

10. Sakai T, Miura H, Yang X. Ultrafine grain formation in face centered cubic metals during severe plastic deformation. Mater Sci Eng A. 2009;499:2-6.

11. Valiev RZ, Islamgaliev RK, Alexandrov IV. Bulk nanostructured materials from severe plastic deformation. Prog Mater Sci. 2000;45:103-89.

12. Guo W, Wang Q, Ye B, Zhou H. Microstructure and mechanical properties of AZ31 magnesium alloy processed by cyclic closed-die forging. J Alloys Compd. 2013;558:164-71.

13. Flausino PCA, Nassif MEL, Bubani FC, Pereira PHR, Aguilar MTP, Cetlin PR. Microstructural evolution and mechanical behavior of copper processed by low strain amplitude multidirectional forging. Mater Sci Eng A. 2019;756:474-83.

14. Alhajeri SN, Gao N, Langdon TG. Hardness homogeneity on longitudinal and transverse sections of an aluminum alloy processed by ECAP. Mater Sci Eng A. 2011;528:3833-40.

15. Zhu QF, Lei LI, Ban CY, Zhao ZH, Zuo YB, Cui JZ. Structure uniformity and limits of grain refinement of high purity aluminum during multi-directional forging process at room temperature. T Nonferr Metal Soc. 2014;24:1301-6.

16. Faria CG, Almeida NGS, Aguilar MTP, Cetlin PR. Increasing the work hardening capacity of equal channel angular pressed (ECAPed) aluminum through multi-axial compression (MAC). Mater Lett. 2016;174:153-6.

17. Stemler PM, Flausino PC, Pereira PH, de Faria CG, Almeida NG, Aguilar MTP, et al. Mechanical behavior and microstructures of aluminum in the Multi-Axial Compression (MAC) with and without specimen re-machining. Mater Lett. 2019;237:84-7.

18. Li YJ, Zeng XH, Blum W. On the elevated-temperature deformation behavior of polycrystalline $\mathrm{Cu}$ subjected to predeformation by multiple compression. Mater Sci Eng A. 2008;483:547-50.

19. Armstrong PE, Hockett JE, Sherby OD. Large strain multidirectiona deformation of 1100 aluminum at 300 K. J Mech Phys Solids. 1982;30:37-58

20. Almeida NGS, Pereira PHR, de Faria CG, Aguilar MTP, Cetlin PR. Mechanical behavior and microstructures of aluminum processed by low strain amplitude multi-directional confined forging. J Mater Res Technol. 2020;9:3190-7.

21. Kapoor R, Sarkar A, Yogi R, Shekhawat SK, Samajdar I, Chakravartty JK. Softening of Al during multi-axial forging in a channel die. Mater Sci Eng A. 2013;560:404-12.

22. Yaghoubi F, Moghanaki SK, Kazeminezhad M. Sound velocity in severely deformed aluminum alloys: AA1100 and AA2024. Appl. Phys. Adv Mater. 2020;126:1-10.

23. Kundu A, Kapoor R, Tewari R, Chakravartty JK. Severe plastic deformation of copper using multiple compression in a channel die. Scr Mater. 2008;58:235-8.

24. Ghanbari BF, Arabi H, Abbasi SM, Boutorabi SMA. Manufacturing of nanostructured Ti-6Al-4V alloy via closed-die isothermal multi-axial-temperature forging: microstructure and mechanical properties. Int J Adv Manuf Technol. 2016;87:755-63.

25. Mu SJ, Hu WP, Gottstein G. Investigations on deformation behavior and microstructure of ultrafine grained two phase Al-Mn alloy fabricated by confined channel die pressing. Mater Sci Forum. 2008;584:697-702.

26. Zhang $\mathrm{S}, \mathrm{Hu} \mathrm{W}$, Berghammer R, Gottstein G. Microstructure evolution and deformation behavior of ultrafine-grained $\mathrm{Al}-\mathrm{Zn}-\mathrm{Mg}$ alloys with fine $\eta$ ' precipitates. Acta Mater. 2010;58:6695-705.

27. Parimi AK, Robi PS, Dwivedy SK. Severe plastic deformation of copper and $\mathrm{Al}-\mathrm{Cu}$ alloy using multiple channel-die compression. Mater Des. 2011;32:1948-56.

28. Kumar SS, Priyasudha K, Rao MS, Raghu T. Deformation homogeneity, mechanical behaviour and strain hardening characteristics of titanium severe plastically deformed by cyclic channel die compression method. Mater Des. 2016;101:117-29.

29. El-Danaf E, Kalidindi SR, Doherty RD, Necker C. Deformation texture transition in brass: critical role of micro-scale shear bands. Acta Mater. 2000;48:2665-73.

30. Sabirov I, Murashkin MY, Valiev RZ. Nanostructured Aluminum alloys produced by severe plastic deformation: new horizons in development. Mater Sci Eng A. 2013;560:1-24.

31. Al-Zubaydi A, Figueiredo RB, Huang Y, Langdon TG. Structural and hardness inhomogeneities in $\mathrm{Mg}-\mathrm{Al}-\mathrm{Zn}$ alloys processed by high-pressure torsion. J Mater Sci. 2013;48:4661-70.

32. Xu C, Furukawa M, Horita Z, Langdon TG. The evolution of homogeneity and grain refinement during equal-channel angular pressing: A model for grain refinement in ECAP. Mater Sci Eng A. 2005;398:66-76.

33. Xu C, Langdon TG. The development of hardness homogeneity in aluminum and an aluminum alloy processed by ECAP. J Mater Sci. 2007;42:1542-50.

34. Wongsa-Ngam J, Kawasaki M, Langdon TG. The development of hardness homogeneity in a $\mathrm{Cu}-\mathrm{Zr}$ alloy processed by equalchannel angular pressing. Mater Sci Eng A. 2012;556:526-32.

35. Wu Y, Baker I. An experimental study of equal channel angular extrusion. Scr Mater. 1997;37:437-42.

36. Kim HS, Hong SI, Seo MH. Effects of strain hardenability and strain-rate sensitivity on the plastic flow and deformation homogeneity during equal channel angular pressing. J Mater Res. 2001;16:856-64.

37. Qiao XG, Starink MJ, Gao N. Hardness inhomogeneity and local strengthening mechanisms of an A11050 aluminium alloy after one pass of equal channel angular pressing. Mater Sci Eng A. 2009;513:52-8. 
38. Xu C, Horita Z, Langdon TG. The evolution of homogeneity in processing by high-pressure torsion. Acta Mater. 2007;55:203-12.

39. Kawasaki M, Alhajeri SN, Xu C, Langdon TG. The development of hardness homogeneity in pure aluminum and aluminum alloy disks processed by high-pressure torsion. Mater Sci Eng A. 2011;529:345-51.

40. Kawasaki M, Ahn B, Langdon TG. Microstructural evolution in a two-phase alloy processed by high-pressure torsion. Acta Mater. 2010;58:919-30.

41. Zhang NX, Kawasaki M, Huang Y, Langdon TG. Microstructural evolution in two-phase alloys processed by high-pressure torsion. J Mater Sci. 2013;48:4582-91.

42. Figueiredo RB, Langdon TG. Development of structural heterogeneities in a magnesium alloy processed by high-pressure torsion. Mater Sci Eng A. 2011;528:4500-6.

43. Kawasaki M, Figueiredo RB, Langdon TG. An investigation of hardness homogeneity throughout disks processed by highpressure torsion. Acta Mater. 2011;59:308-16.

44. Kawasaki M, Figueiredo RB, Langdon TG. Twenty-five years of severe plastic deformation: recent developments in evaluating the degree of homogeneity through the thickness of disks processed by high-pressure torsion. J Mater Sci. 2012;47:7719-25.

45. Panda S, Toth LS, Fundenberger JJ, Perroud O, Guyon J, Zou $\mathrm{J}$, et al. Analysis of heterogeneities in strain and microstructure in aluminum alloy and magnesium processed by high-pressure torsion. Mater Charact. 2017;123:159-65.

46. Hussain M, Rao PN, Singh D, Jayaganthan R, Singh S. Comparative study of microstructure and mechanical properties of Al 6063 alloy processed by multi axial forging at $77 \mathrm{~K}$ and cryorolling. Procedia Eng. 2014;75:129-33.

47. Cherukuri B, Srinivasan R. Properties of AA6061 processed by multi-axial compressions/forging (MAC/F). Mater Manuf Process. 2006;21:519-25.

48. Magalhães DCC, Pratti AL, Kliauga AM, Rubert JB, Ferrante M, Sordi VL. Numerical simulation of cryogenic cyclic closed-die forging of $\mathrm{Cu}$ : hardness distribution, strain maps and microstructural stability. Mater Res Technol. 2018;8:333-43.

49. Huang H, Zhang J. Microstructure and mechanical properties of AZ31 magnesium alloy processed by multi-directional forging at different temperatures. Mater Sci Eng A. 2016;674:52-8.

50. Flausino PCA, Nassif MEL, Bubani FC, Pereira PHR, Aguilar MTP, Cetlin PR. Influence of strain amplitude on the microstructural evolution and flow properties of copper processed by multidirectional forging. Adv Eng Mater. 2020;22:1-13.

51. Yang Y, Mao Q, Zhao Y. Improving the combination of electrical conductivity and tensile strength of Al 1070 by rotary swaging deformation. Results Phys. 2019;13:102235-6.

52. Hu H. Texture of Metals. Texture Stress Microstruct. 1974;1:23358.

53. Pereira PHR, Wang YC, Huang Y, Langdon TG. Influence of grain size on the flow properties of an $\mathrm{Al}-\mathrm{Mg}-\mathrm{Sc}$ alloy over seven orders of magnitude of strain rate. Mater Sci Eng A. 2017;685:367-76.

54. Cao Y, Ni S, Liao X, Song M, Zhu Y. Structural evolutions of metallic materials processed by severe plastic deformation. Mater. Sci. Eng. R Rep. 2018;133:1-59. 